\title{
Molecular Characterization and Pathological Changes of Infectious Laryngotracheitis Virus in Chicken Farms at Ismailia
}

Neven M. ramzy ${ }^{1}$ and Hala M. Ali El-Genaidy ${ }^{2}$

Depts of Virology ${ }^{1}$ and Pathology ${ }^{2}$, Animal Health Research Institute (AHRI) Ismailia branch

\begin{abstract}
Infectious laryngotracheitis (ILT) is an economically important disease of chickens caused by type 1gallidherpesvirus (infectious laryngotracheitis virus, ILTV). Samples from lungs, trachea, liver and spleen were taken, representing 20 farms at Ismailia Province, for molecular studies and histopathological examination on Infectious Laryngotracheitis virus. The samples were obtained from broiler Saso chicken (50 days old) and breeders (65-100 day old) with variable morbidities and mortalities. Four pooled samples from the 20 farms were examined for characterization and identification of ILT virus by PCR. Electrophoretic patterns showed a specific band at $688 \mathrm{bp}$ positive in two samples while it was negative in the other two samples. Samples were genetically characterized as Gallid herpesvirus 1 with similarity to ILTV/Brazil/2007/USP-65 ICP4 by 98\%Gen bank acc. no: gb|FJ477379.1|.The charactrestic histopathological lesions were found in the lung and trachea. The lung showed severe congestion emphysema and collapse. The trachea revealed degeneration and sloughing of tracheal epithelium with hyperemia, edema and leuckocytic infiltrations in the lamina propria and submucosa. The detected virus in this study was genetically characterized as Gallid herpes virus 1 with similarity to ILTV/Brazil/2007/USP ICP4 by $98 \%$. For the prevention on latent infection need to improve recombinant vaccines. The PCR study proved the occurance of ILTV in the respiratory disease complex (RDC) at Ismailia poultry flocks. Recombinant vaccine improvement is recommended as prophylactive measures for the latent infections among chickens.
\end{abstract}

Key words: ILT- PCR- Chickens- Histopathology

\section{Introduction}

Infectious laryngotracheitis (ILT) is caused by gallid herpes virus 1 (GaHV-1). Strains of GaHV-1 of the family Herpesviridae. It is an important highly contagious acute respiratory disease of chickens. It varies widely in virulence but is antigenically homogeneous, affects growth and egg production and may lead to the death (Bagust and Guy, 
1997). Natural infection occurs in chickens and sometimes in pheasants. Transmission occurs via the upper respiratory and ocular routs. ILT virus can establish a carrier state in recovered animals (Bagust, 1985). This is characterized by periods by latency interspersed with episodes of virus shedding detectable by tracheal swabbing (Hughes et al, 1989). Infectious laryngotracheitis virus has the typical morphology of a herpesvirus. Virions have icosahedral symmetry and measure $100 \mathrm{~nm}-110 \mathrm{~nm}$ in diameter. The nucleocapsid contains 162 capsomers which are hexagonal in cross-section with a hole running half-way down the long axis. The core consists of a fibrillar pool on which the single molecule of double-stranded deoxyribonucleic acid (DNA) is wrapped. Surrounding each nucleocapsid is an irregular envelope of $120 \mathrm{~nm}$ $200 \mathrm{~nm}$ in diameter, bearing glycoprotein spikes on the outer surface (Murphy et al., 1995). Chickens are age-dependent resistance to this disease, as most birds under the age of three weeks don't get infected. The disease is well controlled in areas of intensive poultry production by vaccination and biosecurity measures. Control is by the use of live vaccines and hygiene/quarantine practices and the disease is no longer a major disease problem in most countries with developed poultry industries (Biggs, 1982) and (Kirkpatrick et al., 2006). Molecular diagnosis by PCR is considered to be more sensitive than virus isolation for detection of GaHV-1 (Alexander and Nagy, 1997). Pathological lesions of ILTV may be found in the conjunctiva and respiratory tract of infected chickens but are most found in tracheal and laryngeal tissues. A certain percentage of the cases are associated with bronchitis, peribronchitis, pneumonia, necrosis and hemorrhages in the lung. Characteristic intranuclear inclusion bodies in the epithelial cells of trachea are present in many cases (York and Fahey, 1988).

In this study, the detection of ILTV among chickens reared at Ismailia farms was done using the histopathology and the rapid sensitive PCR assay followed by gene sequence analysis that is to show the identity with reference gene sequence.

\section{Material and Methods}

Chickens: broilers (saso chickens) of $60 \%$ morbidities at age 50daysold and from breeders with $20-25 \%$ morbidities at age 65- 100 days-old. Other farms include broilers of 5$8 \%$ mortalities at age 50 days and from breeders with 2-3\% mortalities at age 65- 100 days.

Samples: from lungs, trachea, liver, spleen and kidneys were taken representing 20 farms in Ismailia province. A part of previous organs kept frozen for PCR assay. Another parts kept in $10 \%$ formalin for histopathological examination. 
DNA extraction:DNA extraction from samples was performed using the QIAamp DNA Mini kit (Qiagen, Germany, GmbH) with modifications from the manufacturer's recommendations. Briefly, $200 \mu \mathrm{l}$ of the sample suspension was incubated with 10 $\mu \mathrm{l}$ of proteinase $\mathrm{K}$ and $200 \mu \mathrm{l}$ of lysis buffer at $56^{\mathrm{O}} \mathrm{C}$ for $10 \mathrm{~min}$. After incubation, $200 \mu \mathrm{l}$ of $100 \%$ ethanol was added to the lysate. The sample was then washed and centrifuged following the manufacturer's recommendations. Nucleic acid was eluted with $100 \mu \mathrm{l}$ of elution buffer provided in the kit (Chacon and Ferreira, 2009).

Oligonucleotide Primer: Primers used were supplied from Metabion (Germany) are listed in table (1).

PCR amplification: Primers were utilized in a 25- $\mu$ reaction containing $12.5 \mu \mathrm{l}$ of EmeraldAmp Max PCR Master Mix (Takara, Japan), $1 \mu$ of each primer of 20 pmolconcentration, $4.5 \mu \mathrm{l}$ of water, and $6 \mu \mathrm{l}$ of DNA template. The reactions were performed in an applied biosystem 2720 thermal cycler. PCR cycling condition thermal profile, primary denaturation at $94^{\circ} \mathrm{c}$ for $5 \mathrm{~min}$ and amplification (35 cycles) consists of seconder denaturation at $94^{\circ} \mathrm{c}$ for 30 sec., annealing at $62^{\circ} \mathrm{c}$ for $40 \mathrm{sec}$. Histopathologicansl examination:

The histopathological specimens (lung, trachea, liver and spleen) were fixed in neutral buffered formalin $10 \%$ then processed routinely, sectioned at $5 \mu$ thickness and extension at $72^{\circ} \mathrm{c}$ for $45 \mathrm{sec}$. Final extension at $72^{\circ} \mathrm{c}$ for 10 $\min$ (Chacon and Ferreira, 2009).

\section{Analysis of the PCR Products:}

The products of PCR were separated by electrophoresis on 1.5\% agarose gel (Applichem, Germany, GmbH). Electrophoresis was done in $1 \mathrm{x}$ TBE buffer at room temperature using gradients of $5 \mathrm{~V} / \mathrm{cm}$. For gel analysis, $20 \mu \mathrm{l}$ of the PCR products were loaded in each gel slot. A Generuler $100 \mathrm{bp}$ DNA Ladder (Fermentas, Germany) was used to determine the fragment sizes. The gel was photographed by a gel documentation system, (Biometra, Germany) and the data was analyzed through computer software (Chacon and Ferreira, 2009).

\section{Sequence analysis:}

It was done according to (Chacon and Ferreira, 2009) four the representive samples that were sent for sequencing in Animal Health Research Institute AHRI (El-Dokki, Egypt). The obtained sequences were subjected to nucleotide BLAST tool of the GenBank http:// blast.ncbi. nlm.nih.gov/Blast. $\mathrm{Cgi} / \mathrm{CMD}=$

Web\&PAGE_TYPE=BlastHome then sequences were analysed using MEGA version 6 and BIOEDIT version 7.0.1.4 programs.

and stained with Hematoxylin and Eosin (H\&E) for microscopically examination (Bancroft et al., 1996). 
Table (1): Primers sequences, target genes, amplicon sizes.

\begin{tabular}{|c|c|c|c|}
\hline $\begin{array}{c}\text { Target } \\
\text { gene }\end{array}$ & Primers sequences & $\begin{array}{c}\text { Amplified } \\
\text { segment (bp) }\end{array}$ & Reference \\
\hline \multirow{3}{*}{ ICP4 } & ICP4-1F: & & Chacón and \\
\cline { 2 - 2 } & ACTGATAGCTTTTCGTACCAGCACG & 688 & Ferreira (2009) \\
\cline { 2 - 3 } & $\begin{array}{c}\text { ICP4-1R: } \\
\text { CATCGGGACATTCTCCAGGTAGCA }\end{array}$ & & \\
\hline
\end{tabular}

\section{Results}

\section{Clinical signs:}

The reported clinical signs were characteristic for ILT infection included nasal discharge, coughing, gasping, difficult breathing (with neck extensions and open mouth breathing), coughing blood or blood-stained mucus. Broiler saso chickens (50 day old) in the investigated farms showed $60 \%$ morbidities with average mortalities between $5-8 \%$ while the breeders at age 65-100 day old exhibited 20$25 \%$ morbidities and $2-3 \%$ mortalities.

\section{Postmortem examination:}

The characteristic postmortem lesions are pronounced in the larynx, trachea and lung. Larynx and trachea were hyperemic with increase of mucus and yellow white cream like exudate. Excessive coats of the larynx while the trachea showed catarrhally, hemorrhagic to fibrinous inflammation (severe laryngotracheitis).

\section{PCR and Sequence:}

Four pooled samples were chosen from all samples for examination and detection of ILT virus by PCR. Electrophoretic patterns showed a specific band at $688 \mathrm{bp}$ positive in two samples while it was negative in the other two samples.

Samples were genetically characterized as Gallidherpesvirus 1 with similarity to ILTV/Brazil/2007/USP-65 ICP4 by $98 \%$ Gen bank acc no: gb|FJ477379.1|.

\section{Histopathological results:}

Microscopical examinations of the trachea showed the presence of tracheal cellular exudates in the lumen, necrosis and sloughing of tracheal epithelium, congestion and edema in lamina propria and submucosa as well as infiltration of mucosa with inflammatory cells mainly lymphocytes (Fig. 2\&3).

The lung revealed degeneration of the bronchi and bronchioles, emphysema and collapse, congestion, hemorrhages as well as mononuclear cell infiltrations (Fig. 4).

The liver suffered vacuolar degenerative changes and hepatic cells necrosis, edema as well as severe congestion of central vein, and hepatic sinusoids (Fig.5 \& 6).

The spleen displayed edema, hemorrhages, congestion of splenic blood vessels and lymphoid depletion in white pulp (Fig.7 \& 8). 


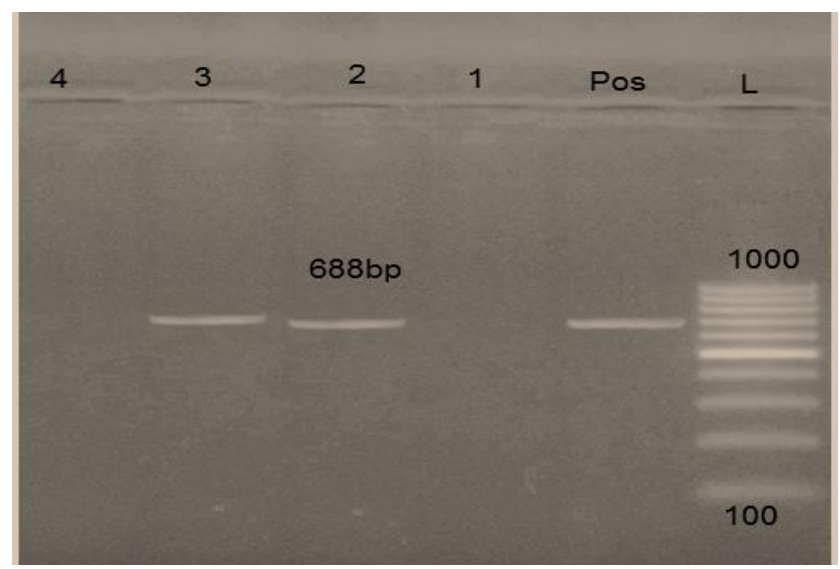

Fig (1): Gel electrophoresis showing 100bp ladder (L) 688bp band with positive controland positive s imples (lane 2,3) and no band were observed in negative control (lane 1,4).
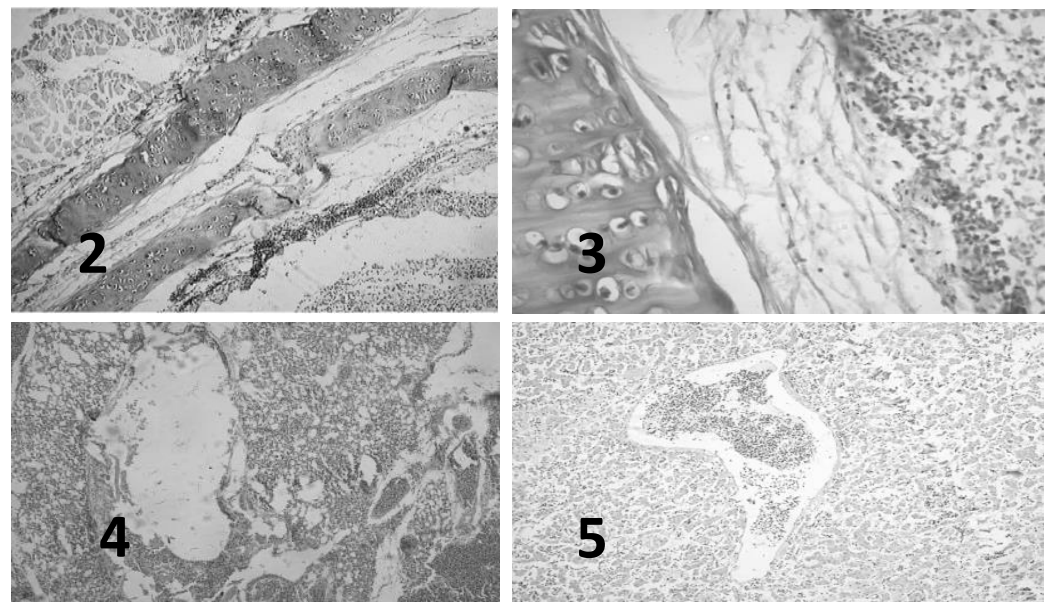

Fig. (2): Trachea of ILT infected chickens showing cellular exudate in lumen, necrosis and sloughing of tracheal epithelium as well as edema and inflammatory cells infiltrations. H\&E stain. X100.

Fig. (3): Trachea of ILT infected chickens showed edema in perichonderium and submucosa as well as leukocytic cellsinfiltrations. H\&E stain. X400

Fig. (4): The lung showing emphysema and collapse, congestion, hemorrhages as well as mononuclear cell infiltrations H\&E stain. X100.

Fig. (5): Liver showing vacuolar degenerative changes and hepatic cells necrosis, edema as well as sever congestion of central vein and hepatic sinusoids. $H \& E$ stain. X250. 


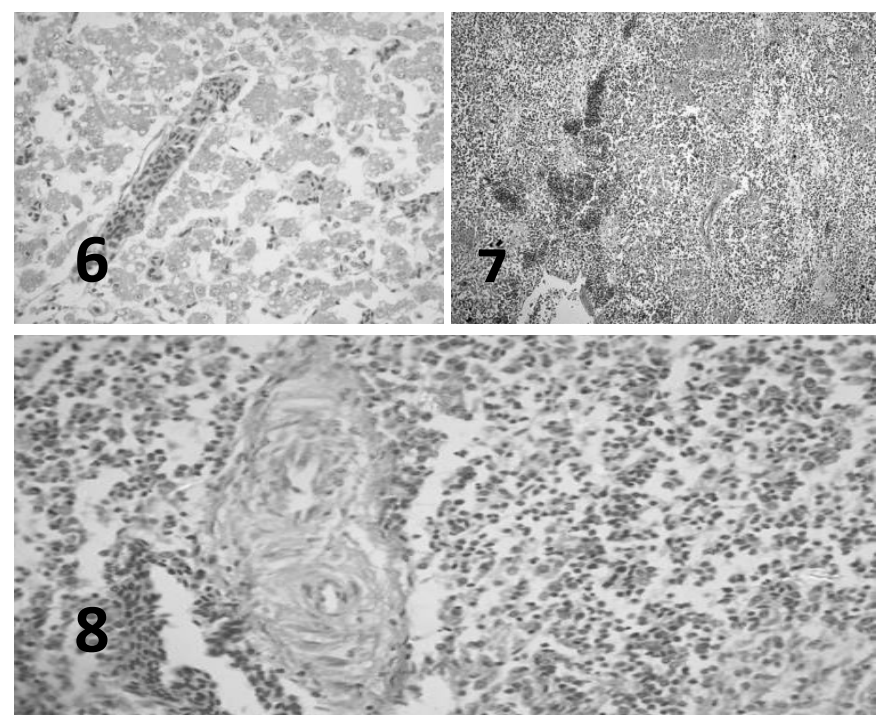

Fig. (6): Higher magnification of fig. (5). H\&E stain. X400.

Fig. (7): The spleen of ILT infected chickens showing edema, hemorrhages congestion of splenic blood vessels and lymphoid depletion in white pulp. $H \&$ E stain. X100.

Fig. (8): Higher magnification of fig. (7). H\&E stain. X400.

\section{Discussion}

In the present study, the clinical signs related to ILT virus included nasal discharge, coughing, gasping, difficult breathing (with neck extensions and open mouth breathing), coughing blood or blood-stained mucus and this agree with

(Robertson

and

Egerton, 1981). Post-mortem findings reported in this study were characteristic to ILTV infection (severe laryngotracheitis often with blood in lumen). In present study, the gross lesions are mostly found in trachea and larynx where they appeared congested. This result agreed with (Trevor and James, 1988).

Broiler Saso chickens showed $60 \%$ morbidities at age 50days- old while breeders showed 20-25\% morbidities at age 65-100 days-old. Broilers suffered 5-8\% mortalities at age 50 days but breeders with 2-3 $\%$ mortalities at age 65- 100 days. PCR has been useful and sensitive test in detecting ILTV. In the present study, electrophoretic patterns showed a specific band at 688bp positive in two samples while it was negative in the other two samples.

In chickens, the main site of acute ILT virus replication is the trachea, which is innervated through a number of ganglia (BubienWaluszewska, 1981). (Williams et al., 1992) reported that, PCR assay was useful tool to confirm the ILTV. PCR was more sensitive for virus isolation from clinical 
samples. PCR diagnosis of ILTV is correlated with the characteristic clinical signs and pathology of ILT observed in birds. PCR and virus isolation were similar in sensitivity, but PCR was superior in the recovery phase. A number of ILTV genes can be targeted for PCR followed by nucleotide sequence analysis of the resultant amplicons for strain identification purposes, For example, ICP4 (infected cell protein 4) may be amplified by PCR using the primers described by (Chaconand Ferreira, 2009) and the resultant amplicons purified using a disposable mini column method and submitted to bidirectional DNA sequencing using the PCR primers as sequencing primers. Various software programs including cluster $\mathrm{W}$ may be used for analysis of the sequences and comparison with the existing sequences in GenBank. It should be noted that sequence analysis of multiple genes may be required for proper identification of the ILTV strains.

Histopathologically, lesions of ILT are pronounced in trachea and lung. The virus affects the epithelial cells primarily and inflammation develops in submucosa and underlying parts. ILT infection is characterized by pathognomonic intranuclear inclusion bodies in respiratory and conjunctival epithelial cells. Intranuclear inclusion bodies may be detected in tissues stained with Giemsa or Hematoxylin and Eosin.
Histopathological examination for the detection of inclusion bodies is considered rapid results within 24 hours post infection (Guy et al., 1992). This can explain the undetectable inclusion bodies in the present study.

(York and Fahey, 1988) stated that degeneration, necrosis, hemorrhages and the destruction taking place at later stages in trachea. Cellular infiltration and hemorrhages are due to secondary invading bacteria. Early changes in tracheal mucosa include the loss of goblet cells and infiltration of mucosa with inflammatory cells as the viral progress. Later, cell destruction and desquamation result in lacking any epithelial covering of the mucosal surface.

Blood vessels with the lamina propria may protrude into tracheal lumen. Hemorrhages may occur in cases of severe epithelial destruction and desquamation with exposure and rupture of blood capillaries (Vanderkop, 1993). These results were in agreement with our results.

\section{Conclusion}

Detected virus was genetically characterized as Gallid herpes virus 1 with similarity to ILTV/Brazil/2007/USP ICP4 by 98\%. The study proved the involvement of ILTV in respiratory disease complex (RDC) in Ismailia poultry flocks using PCR. Therefore, the prevention on latent infection needs to improve recombinant vaccines. 
Referances

Alexander H.S. and Nagy E. (1997): Polymerase chain reaction to detect infectious laryngotracheitis virus in conjunctival swabs from experimentally infected chickens. Avian Dis.; 41:646-653.

Bagust, T.J. (1985): Infectious laryngotracheitisherpesvirus (ILT): latency detection and in vitroreactivation of haemorrhagic and vaccine strains. Proceedings of the VIIIth International Congress of theWorld Veterinary Poultry Association, Jerusalem, Israel, Program and Abstracts, p. 23.

Bagust, T. J. \& Guy, J. S. (1997): Laryngotracheitis.

In Diseases of Poultry, 10th edn, pp. 527-539.Edited by B. W. Calnek, H. J. Barnes, C. W. Beard, L. R. McDougald\& Y. M. Saif. Ames: Iowa State University Press.

Bancroft,J.D.; Stevens, A. and Turner, D.R. (1996): Theory and practice of histological technique " 4th Ed. Churchill in Livingstone, New York.

Biggs, P.M. (1982): The world of poultry disease. Avian Pathology, 11: 281-300.

Bubien-Waluszewska, A. (1981): The cranial nerves. In form and Function in Birds, vol.2, pp.385438. Edited by A. S. king and J. Mclell and. London and NewYork: Acd.press.

Chacon, J.L. and Ferreira, A.P.J. (2009): Differentiation of field isolates and vaccine strains of infectious laryngotracheitis virus bt
DNA sequenceing vaccine. 27: 6731-6738.

Guy, J.S., H.J. Barnes, and L.G. Smith (1992): Rapid diagnosis of infectious laryngotracheitis using a monoclonal antibody-based immunoperoxidase procedure. Avian Pathol. 21:77-86.

Hughes CS, Gaskell RM, Jones RC, Bradbury JM, Jordan FTW. (1989): Effects of certain stress factors on the re-excretion of infectious laryngotracheitis virus from latently infected carrier birds. Research in Veterinary Sciences; 46:247-276.

Hughes CS, Williams RA, Gaskell RM, Jordan FT, Bradbury JM, et al. (1991): Latency and reactivation of infectious laryngotracheitis vaccine virus. Arch Virol 121: 213-218.

Kirkpatrick, N.C., Mahmoudian, A., Colso, L. A., Devlin, J.M. and Noormohammdi, A.H.(2006): Relationship between mortality, clinical signs and tracheal pathology in infectious laryngotracheitis. Avian pathology, 35:449-453.

Mahmoudian A, Kirkpatrick NC, Coppo M, Lee SW, Devlin JM,. (2011): Development of a SYBR Green quantitative polymerase chain reaction assay for rapid detection and quantification of infectious laryngotracheitis virus. Avian Pathol 40: 237-242.

Murphy, F.; Fauquet, C.M.; Bishop, D.H.L.; Ghabrial, S.A.; Jarvis, A.W.; Martelli, G.P.; Mayo, M.A. and Summers, 
M.D.(1995): Classification and nomenclature of viruses. Archives of Virology Supplementum, 10,268274.

Roberson, G.M. and Egerton, J.R.(1981): Replication of infectious laryngotracheitis virus in chickens following vaccination. Australian Journal,57:119-123. veterinary

Trevor, J. Bagust, James and S. Guy (1988): Laryngeotrachieitis. Diseases of poultry.10th Ed. PP 527-539.

Vanderkop, M.A. (1993): commercial broiler chickens. Can. Vet. J. 34:185.

Williams RA, Bennett M, Bradbury JM, Gaskell RM, Jones RC, Jordan FT.(1992):

Demonstration of sites of latency of infectious laryngotracheitis virus using the polymerase chain reaction. J Gen Virol. ;73(Pt 9):2415-2420.

York, J.J. and Fahey, K.J. (1988): Diagnosis of infectious laryngotracheitis using a monoclonal antibody ELISA. Avian Pathol

Infectious laryngeotracheitis in

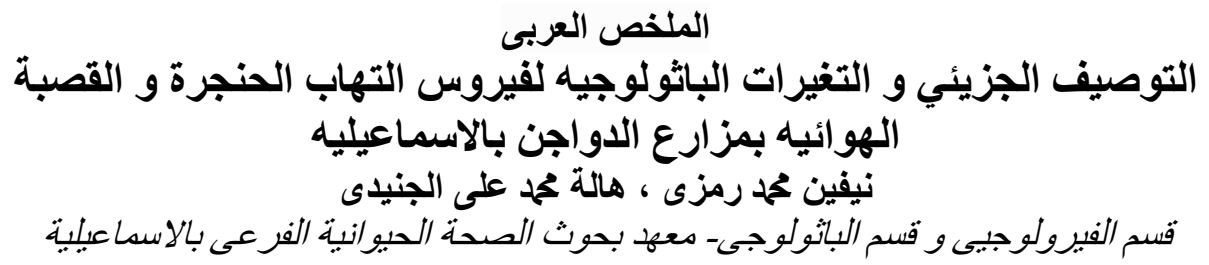

قد تم أخذ عشرون عينه من مزارع الدواجن (الساسو) التى ظهر عليها أعراض مرض التهاب التهاب

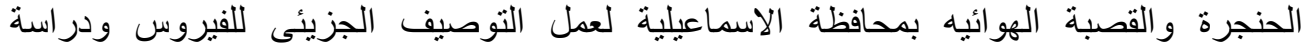

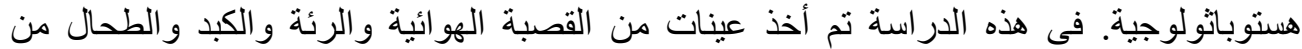

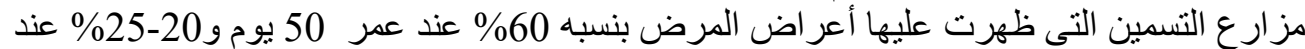

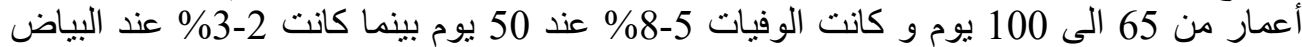

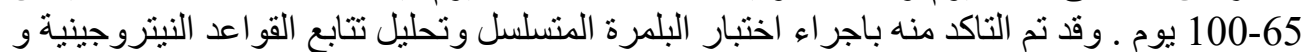

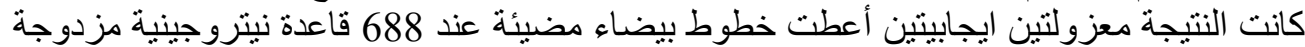

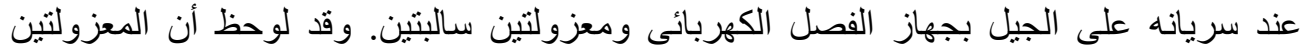

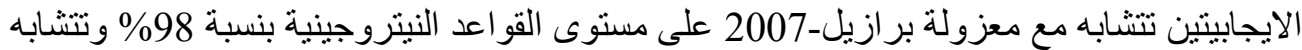

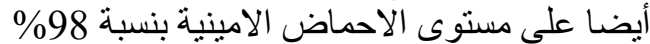

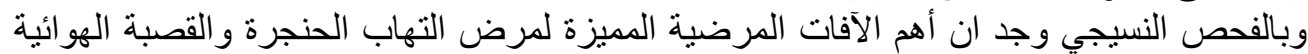

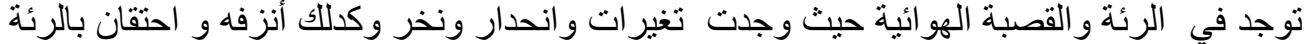

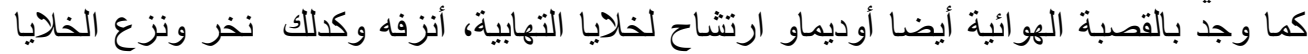
المبطنة لسطح البشرة. هذه الدراسة اثتتت أن فيروس التهاب الحنجرة والقصبة الهوائية هو أحد المسبيات فى حالات

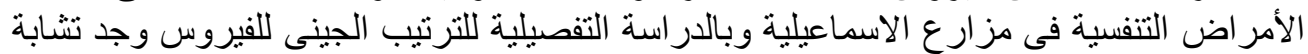
بنسبة 98\% مع العترة البر ازيلية 2007 و نوصى والإعى باستخدام العثرات المناسبة فى التحصينات للوقاية من هذه العترات المعزولة. 